\title{
Perceptions of the Performance, Goals and Characteristics of Hospital Alliances: A Multi-national Study
}

\author{
Daniel Pelletier ${ }^{1, *}$, Frances Wildhaber ${ }^{2}$, Pierre Collerette $^{1}$, Michael Heberer ${ }^{2}$ \\ ${ }^{1}$ Department of Administrative Sciences, University of Quebec in Outaouais, Canada \\ ${ }^{2}$ Institute of Surgical Research and Hospital Management, University Hospital of Basel, Switzerland
}

Copyright $\bigcirc 2016$ by authors, all rights reserved. Authors agree that this article remains permanently open access under the terms of the Creative Commons Attribution License 4.0 international License.

\begin{abstract}
A mixed methodology study of inter-hospital alliances in Germany, Canada and Switzerland was conducted to describe the goals and performance of inter-hospital alliances and to identify which alliance features best predict performance. Alliance features and performance were studied through a series of 59 interviews conducted within 12 hospitals involved in such partnerships. Respondents included administrative, medical and nursing staff. A standardized interview schedule was used to document the perceived as well as factual attributes and performance of the inter-hospital alliances they were included in. Results indicated that financial goals were not rated as being as important as improvements regarding service access and quality. A path analysis generated a seven component model of features linked to the perceived success of alliances: environmental, human and structural components of the alliances had an indirect relationship with overall success which was mediated through adaptability. Inter-hospital alliances have similar goals with regards to service quality and access, .notwithstanding the country, the type of health care system and the respondents.
\end{abstract}

Keywords Hospital Alliances, Model, Management, Success Factors

\section{Introduction}

Under new competitive environments, alliances represent one possible venue for value creation in order to allow hospital repositioning by influencing its market- and competitive position [1]. Depending on the country being studied, alliances in the healthcare industry are a comparatively new occurrence driven by increasing environmental pressure on the healthcare providers. Interactions between medical professionals may be driven by different incentives (e.g. medical expertise and reputation rather than profit margins) and alliance drivers differ from other industries with issues like IP appropriation, balance sheets, capital and branding playing a minor to non-existent role, while aspects such as acquiring more customers, infrastructure access, cost/risk reduction are common to the different industries' alliances. We can therefore expect some unique aspects of inter hospital alliances.

Effective alliance management is critical in order to maximise the alliance outcome, of which governance is one critical component. The theory behind alliance governance is approached in two ways, the structural or formal approach, which relies on the importance of a binding contract between the parties and the relational perspective focusing on trust development and behaviour [2]. In the German telecommunication industry, the optimal configuration of formal and relational governance mechanisms was shown by Hoetker and Mellwight[3] to depend on the asset type and emphasised the necessity to match the assets to the governance type in order to ensure successful alliance performance.

Knowledge-based assets (as available in healthcare as opposed to property-based assets) exhibit poor predictability for appropriate processes and outcomes, are best suited to relational governance with for example, trust-building, shared decision-making and problem-solving [4]. According to Gulati and Singh[5], alliances with a technology component, which are highly independent and with appropriability concerns are more likely to have a greater hierarchical governance structure [6].

Albers et al.[7]. Proposed five key design components (interface, intraface, specialisation, formalisation and centralisation) to describe the alliance configurations. In a study of cross-border alliances, while Emden et al.[8] focused on learning from past experience as a key factor in enhancing alliance performance. This concept is also integrated in multiple publications on institutionalising alliance experience/capability or cooperative competency 
$[1,9,10]$, arguing for competitive advantage by internalising alliance know-how. Trust development between partners is one of the most important core components shown to be associated with successful outcomes [11] and opportunistic behaviour is, as expected, negatively related.

A study of 186 small Swiss companies [12] also showed that mutual trust was the most important variable followed by prior positive experience with the partner, whereas formalisation, or financial involvement ranked to be of comparatively low importance. In addition to these factors, Mohr \& Spekman[13], along with Zaman \& Mavondo[14], identified commitment, communication, joint planning and conflict resolution techniques as factors which helped to align the partners. Whipple \& Frankel[15], in addition to identifying similar key success factors, observed that it was important that partners identify and agree on the success factors that are applicable to their relationship, be it trust, clear goals, people skills or senior management support.

The literature on alliances is replete with papers identifying best practices or laying out suggestions derived from various sources with unequal empirical support; some are research-based, some appear to be linked to models or theories of management and some even present their suggestions as self-evident. The literature on alliance success factors does include a few attempts at modelization, using alliance success $[13,14]$ or performance [16] as outcome or dependent variables. Furthermore, Albers, Wohlgezogenn \& Zajac[7] have published a descriptive model of alliances concerned mainly with their structure and typology. It must be noted that none of these models has been empirically tested. Their validity is therefore theoretical or procedural at best.

Alliances in the health care sector, excluding the pharmaceutical industry, operate under a different set of rules for a host of reasons. Success is easily measured in the industrial, commercial or financial sectors, with quarterly gains being the main focus. However, in the health sector the outputs are numerous, gains are often replaced by the search for diminished costs. Individual and collective expectations are more in tune with health concerns than with financial issues, especially in public systems. One cannot simply apply standards, recommendations and suggestions stemming from one sector to the other.

Financial constraints have forced hospital administrators to consider various types of alliances in order to offset, stabilize or share with partners the rising costs of health care $[10,17,18]$, but the absence of any significant economic advantage in some alliances has been documented [19-22]. Non-financial outcomes such as innovation, better services, staff attraction and retention, and corporate image have been much less studied in the health care system. Their structure, governance and day-to-day management vary and, to our knowledge, no health care specific guidelines for alliance conception and operation appear to be empirically supported. Inter-hospital alliances have been described mostly through individual case studies, and empirical comparative research is very scarce in this sector. Furthermore, they have not been studied as extensively as commercial or industry-based alliances; therefore, an examination of their goals, structure, and perceived success is warranted.

\section{Objectives}

The objectives of the study were as follows:

1. To describe the goals, expectations and performance of inter-hospital alliances.

2. To identify alliance features associated with a positive impact on the alliance performance.

Three research questions were investigated:

a) What are the goals and expectations of inter-hospital alliances?

b) Are goals and expectations met with success?

c) Are there sufficient communalities in alliance features to generate a model of factors associated with success?

\section{Methods}

\subsection{Participants}

Hospital CEOs were solicited to take part in the research if they had an alliance with one (or more) independent hospital with the aim of providing patient services. A total of twelve institutions situated in three different countries (Switzerland, Germany and Canada) agreed to take part in the study, their size ranging from small to large; all but one were public institutions. A wide range of alliance therapeutic fields was included: oncology, cardiovascular, central nervous system, paediatric, metabolic diseases, radiology and trauma. The complexity of alliances ranged from a simple dyad with provision of a single defined patient service, through bilateral collaborations creating a new separate entity, all the way up to large regional networks. Participants for the interviews $(\mathrm{N}=59)$ were selected and identified by the CEO of each institution; 16 interviews were conducted in three sites in Canada, 17 interviews in three Swiss hospitals and 26 interviews in six German sites. Participants represented at least three levels in the alliance structure, namely the senior hospital management level $(n=17)$, the alliance management level $(n=21)$ and the operating $\operatorname{staff}(n=21)$.

\subsection{Instruments}

A 56 item standardized interview schedule including both open and fixed alternatives questions was designed for this study, based on a preliminary questionnaire designed and used in a pilot study conducted by two of the authors [23]. A variety of alliance characteristics were investigated: rationale, targets, processes, experience in alliance, 
competitive pressures, governance size, mechanisms and involvement, power structure, cooperation practices, trust, and alliance success and performance. In addition to the standardized questions, time was reserved at the end for comments regarding the interviewees' overall perception of the alliance. The questionnaire was prepared in English and translated into French and German by native speakers. It was tested in a pilot run in interviews performed in English, French and German to check clarity and consistency and the questionnaire thereafter adapted where necessary. The interviews usually lasted between 45 and 90 minutes.

\subsection{Procedure}

In each participating hospital a confidentiality disclosure agreement was executed and background documentation relating to the formal aspects of the alliance gathered. Interviews were scheduled with each participant and were recorded when respondents agreed, while at the same time the interviewer rated the participants' answers on a systematic content analysis coding grid with quantitative outcomes. Coding reliability was assessed by comparing ratings of selected interviews generated by two different raters. Discrepancies were discussed and corrected. The final rater agreement score was high $(94,3 \%)$. Coded interview results were then triangulated with the respondents; four of them requested minor changes which were implemented.

\subsection{Data Treatment and Analytic Strategy}

All documents were translated into English and quantifiable responses entered into an SPSS database. Factual data gathered from publicly available sources or official documents was cross-checked with the appropriate administrative staff at each site and included in the transcribed interview submitted for approval to each interviewee. The compiled data was summarised and again cross-checked for accuracy between interviewers. Quantitative data from each respondent were tallied and averaged while qualitative information gathered through open questions and comments made at the end of the interview were compiled. Individual items were merged into aggregate variables: competition (from within the alliance and the environment); complexity (the number of partners and the network structure); experience (number and duration of previous and present alliances); trust and cooperation (between alliance partners and among staff); governance status (hierarchical position of the alliance governance board); adaptability (changes made to the alliance); goals or expectations; and overall success (combination of perceptions of possible financial gains or lower costs, innovation, client and staff attraction). Descriptive statistics and ANOVAs were used to describe goals, expectations and performance (success) of the alliances; a path analysis was performed to identify how various alliance features interact and predict overall alliance success.

\section{Results}

A total of seven different categories of goals or expectations were tallied from the interview material. The mean importance of each goal for each of the respondents was computed on a three point scale, with 3 representing the highest score (see Figure 1).

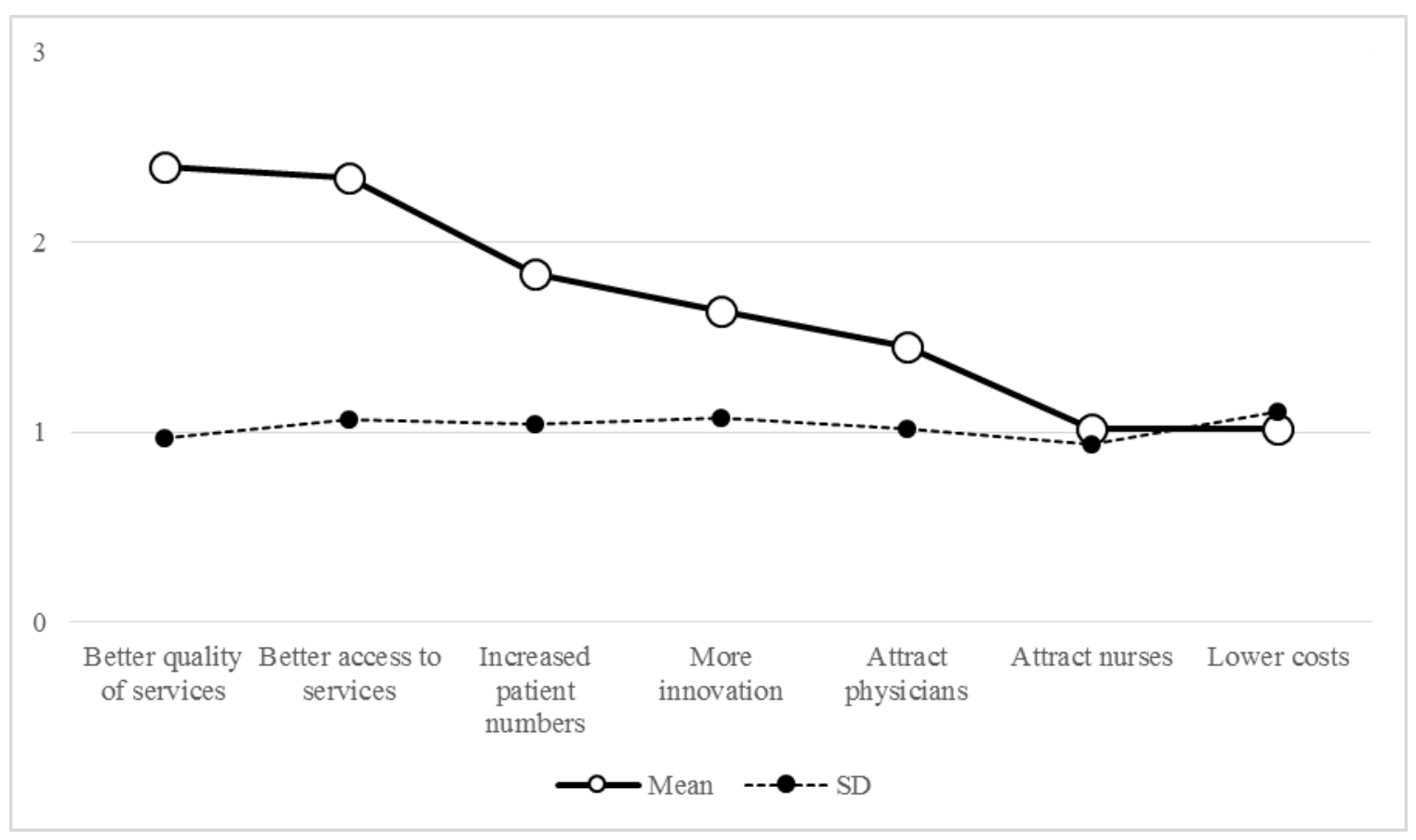

Figure 1. Mean importance score and S.D. for alliance goals and expectations 
Better quality and access to services generated the highest mean scores, while attracting nursing staff and lowering costs were last. Standard deviations were similar for all goals, indicating the presence of a bi-modal distribution fort the latter two variables. Itemized success (or performance) scores were then compared with the corresponding mean importance score for each goal or expectation and an goal vs performance gap was computed. Positive scores indicated that performance exceeded goals and expectations, while negative scores indicated the opposite: results were below what was expected (see Figure 2). Six of the categories of goals/expectations showed moderate to small positive gaps, while lower costs generated the only negative gap: results were lower (albeit by a very small margin) than what was expected.

Further analyses were conducted to ascertain the presence of possible differences in overall success scores linked to the country, category of respondent, alliance partner selection criteria, presence of alliance targets and written alliance rules. In order to allow the use of parametric tests, analyses were conducted using the coded quantitative data generated by each respondent $(\mathrm{N}=59)$. One way ANOVA tests revealed no significant effect linked to any of these factors (see Table 1).

A path analysis was performed on the data using overall success as the dependent variable, with competition, complexity, experience, cooperation, governance status and adaptability in the predictor set (see Figure 3). Non-significant aggregate variables included trust, governance size, goal setting, alliance results monitoring, partner selection criteria and conflict resolution provisions in the alliance. Overall success was significantly linked to adaptability, which in turn was predicted by cooperation, on the one hand, and governance status, on the other hand. Finally, governance status was predicted by three variables: competition, complexity and experience in alliances.

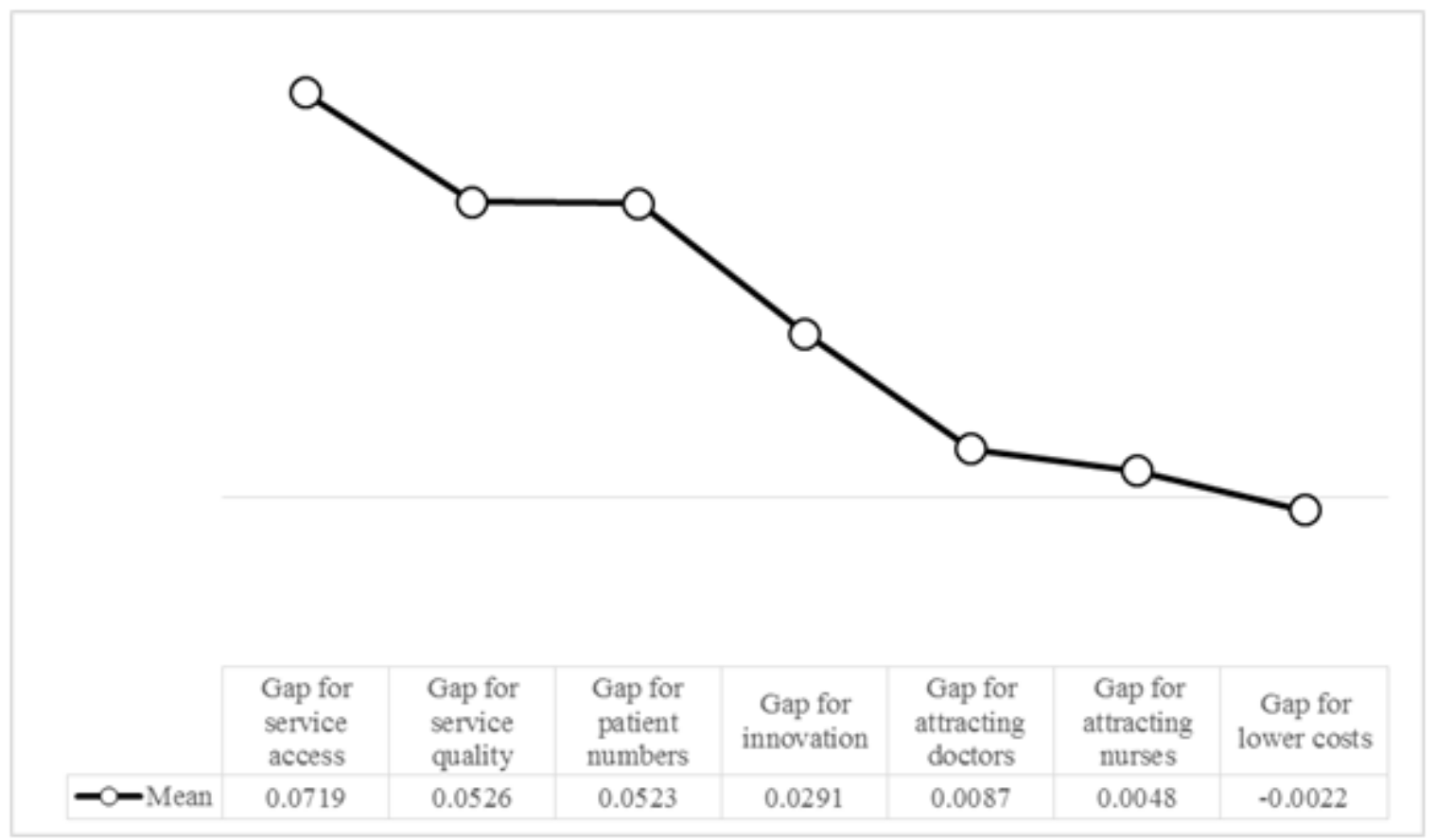

${ }^{1}$ The scale of the figure has been enlarged. Gaps are based on a 3 point scale.

Figure 2. Mean gap ${ }^{1}$ between goals and performance scores

Table 1. Anova results for selected factors with overall success as a dependent variable

\begin{tabular}{|c|c|c|c|}
\hline Factors & $\operatorname{Mean}^{2}$ & $\mathbf{F}$ & Sig. \\
\hline Country (Canada, Switzerland, Germany) &, 529 &, 886 & ,628 \\
\hline Respondent status (physician, administrator, nursing staff) & ,708 &, 657 &, 863 \\
\hline Alliance partner selected with due diligence & ,972 & ,473 & ,973 \\
\hline Alliance targets exist or not & ,290 & 1,457 & ,243 \\
\hline Written rules for alliance operation &, 575 & 1,424 & ,203 \\
\hline
\end{tabular}




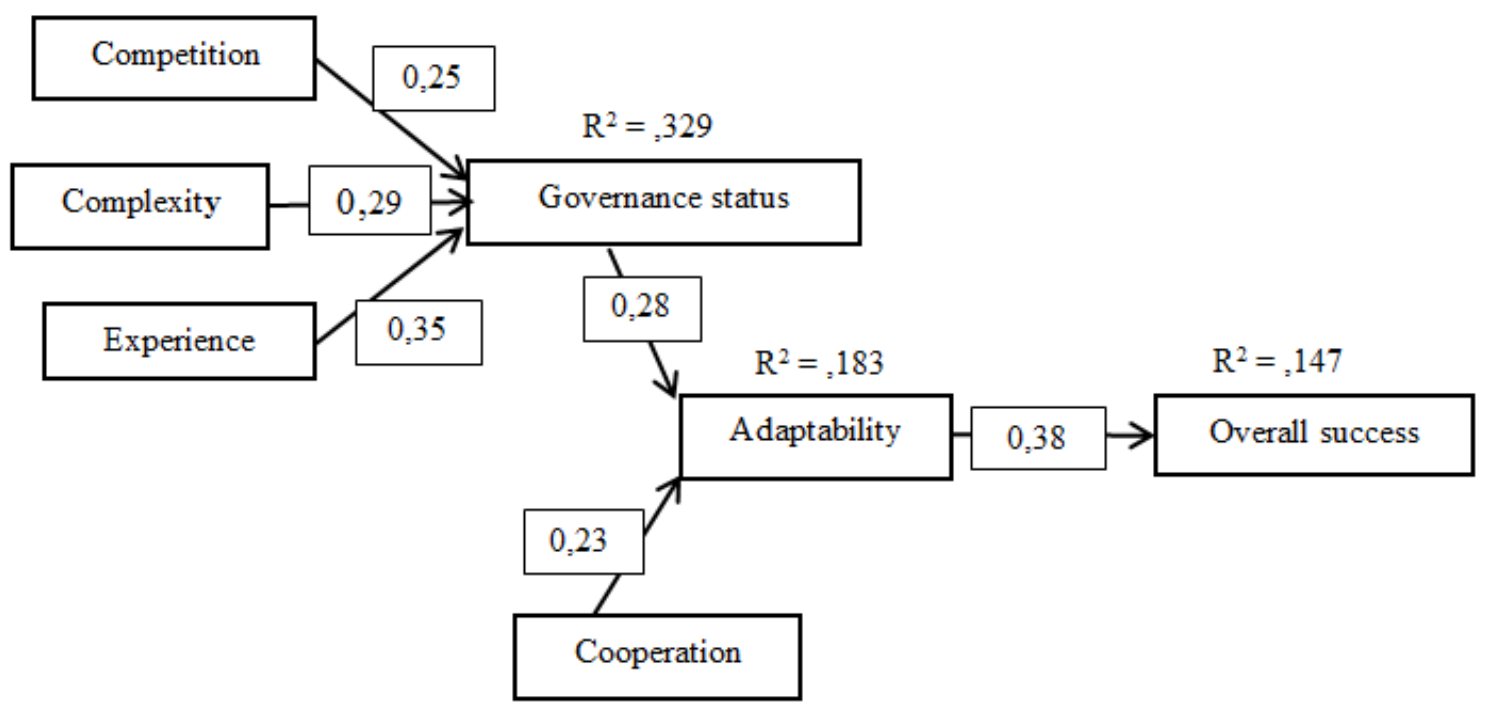

Figure 3. Path analysis of the relationships between alliance characteristics and overall success

\section{Discussion}

The discussion will follow the sequence of the three research questions.

\subsection{What are the Goals and Expectations of Inter-hospital Alliances?}

The overall trend regarding hospital alliances goals places at the forefront better quality and access to services, followed by increases in patient numbers, more innovation and attracting physicians. Attracting nursing staff and lowering costs have the lowest priorities. This clear emphasis on better services is probably a reflection of the public status of 11 out the 12 hospitals from which the sample of respondents was drawn. Public hospitals are generally faced with dire financial constraints [24-26], and improving both quality and access to services could be the only realistic goals for the respondents. These goals were measured through perceptions since documented targets and systematic monitoring were lacking throughout. Increasing patient numbers ranked lower than improving access, which could indicate that better access does not go hand in hand with more clients, since problems caused by understaffing, increasing client numbers, and overcrowding in emergency wards appear to be universal in the public system [27-32]. Lowering costs generated the lowest scores. Thus, financial gains or savings through alliances do not appear to be a priority for the respondents. The prime objective of alliances concluded in other sectors is financial: generating profits, maintaining a competitive edge and lowering costs is of paramount importance. This does not mean that these are not valid objectives for healthcare, from a monetary and governmental perspective; but our respondents valued services more, probably because approximately two thirds of them were on the front line (physicians and nursing staff). This poses the problem of alliances which are structured and endorsed specifically to try to reduce costs. The fact that this goal did not get a higher priority rating when finances are at the heart of all large scale decisions affecting public healthcare suggests that financial and clinical imperatives are not equally shared nor are they included in a global perspective; rather, they seem to be defended by different proponents $[33,34]$. It must be noted that the standard deviations of the goal means were all around 1,0 on a three point scale. This has an impact on two goals: attracting nursing staff and lowering costs, which both have a similar mean of 1,0 . This bimodal distribution means that most of the respondents rated that goal with scores of 0 and 2 , thus as not important or important. It was not possible to identify communalities between respondents scoring either at the low or the high end of the distribution.

\subsection{Are Goals and Expectations Met with Success?}

In order to determine if goals and expectations identified by the respondents were met with success, a goal/success gap was computed for each outcome variable. The only negative gap (at best a very slim one) was generated for cost reductions, which were slightly lower than expected. None of the respondents could financially quantify that gap, in the absence of alliance specific auditing procedures. This begs one question: within hospital alliances, what is success? How is it best measured? [35,36]. Obviously, this question must be answered in reference to the initial alliance objectives and targets, which appear to be sorely lacking here, especially with regards to financial variables. This leaves it up to each respondent to try to approximate what the goals are, and how successful the alliance was at reaching them. Therefore, there is a definite risk of a social desirability bias here [37,38], with performance being equated with each individual's perception of success, and a tendency to rate goals and performance with a favorable 
bias which reflects positively on the respondent's role in attaining these results. Conversely, the perception of negative financial outcomes could be linked to a public healthcare zeitgeist fueled by years of cuts and restrictions, especially in the absence of objective data derived from financial records. This underscores the need for more factual and quantitative indicators that should be woven into the alliance agreement at the onset [39].

\subsection{Are There Sufficient Communalities in Alliance Features to Generate a Model of Factors Associated with Success?}

In order to control for possible extraneous factors which could influence the overall success rating, the following factors effect were tested: country, category of respondent, alliance partner selection criteria, presence of alliance targets and written alliance rules. No significant effect of any of these factors was found, indicating the presence of certain communalities which were compatible with a path analysis. With a 1:8 component to participants ratio, the sample size was sufficient to meet the bare bones approach to path analysis, i.e. a minimum of five to ten participants per component [40]. The seven components model generated by the data places adaptability in a direct relationship with overall success, This signifies that according to our respondents, an alliance's ability to change and to adapt to circumstances is the best single predictor of success. Adaptability is strongly contingent on cooperation, a second tier factor, which is self-explanatory considering the number of staff which is influenced by changes within the structure and the services provided by an alliance. The other second tier factor affecting adaptability is governance status. This means that the status of the alliance governance, which can range from line staff all the way to CEOs, influences the depth and the effectiveness with which changes are identified and implemented. Three third tier factors were significantly linked to governance status: competitive pressures, the complexity of the alliance and experience in actual and previous alliances. One could hypothesize that both competition and alliance complexity increase the need for strong executive governance, especially when interests collide and partners try to negotiate individual or specific advantages. As far as the effect of experience is concerned, some research has shown that long lasting alliances tend to lower the frequency and the quantity of direct information shared by partners [41,42], with transactions being routinely approved in a bureaucratic way over time. The impact of experience on the governance status may be explained by a process of delegations, with high ranking alliance representatives being the only ones authorized to sign off on certain decisions. However, no published research has studied this issue.

The model derived from the data collected presents a few similarities with some characteristics of the theoretical or untested models designed to study generic alliances, i.e. not in the healthcare field. In the Mohr \& Spekman model[13]., alliance or partnership success is equally linked to three series of factors: partnership attributes (such as commitment, coordination, trust and interdependence); communication behavior (quality of communication, information sharing and participation); and various conflict resolution techniques. Without empirical support to compare both models, one can only observe that some of the components are somewhat similar.

Zaman \& Mavondo's model [14]. is more complex and includes both direct, indirect and moderated influences of various characteristics on alliance success. They proposed a direct relationship between the environment and alliance characteristics along with an indirect network of links between the partnering firms' characteristics and success, with alliance structure and transactions posing as intermediate or moderating variables. The model tested here partly replicated these links with one important caveat: variables are not sufficiently defined in the aforementioned model, while they were measured in the present study. Therefore, one cannot guarantee that success (or any other construct) was defined (or measured) the same way across studies. The same could be said concerning Das \& Teng's model [16] and Heimericks and Duysters' research [43]: partner characteristics directly influence the nature and operation of the alliance which in turn determine the degree of success or performance.

This illustrates an important problem: limited possibilities for replication. There is no clear scientific tradition or methodology in the field of alliance success and every author more or less creates his own set of variables and markers in his research. This generates a large number of variables which have been previously studied: experience, trust, cooperation, communication, structure, governance and so forth. However, all of the above are measured with different approaches, instruments and designs ranging from single case studies with unstructured interviews to quantitative correlational research. This points to the relative youth of the field which will only benefit from replications. The only objective variable which is common to all partners and alliances is financial: how much does it cost, how much did we save. However, there were no distinct financial data on alliances according to our respondents, mostly because hospital and alliance specific operations are intertwined in a common accounting system.

\subsection{Study Limitations \& Suggestions for Further Research}

This study has been conducted with a large number of respondents, in terms of qualitative interviewing, but it still is limited as far as statistical power is concerned, especially for parametric analyses. These results should thus be validated with a larger sample, enabling goodness of fit analyses. Single subject/method bias is possible here, most of the information having been collected through individual interviews. Finally, financial information or human resources reports were not readily available from the 
participants. Further research should concentrate on replicating some of the better studies published in the field; governance and outcomes should be studied with hard data and fine grained measures both in the public and private sectors.

\section{Conclusions}

The objectives of this study were to describe the goals, expectations and performance of inter-hospital alliances, and to identify alliance features associated with a positive impact on the alliance performance. Inter-hospital alliances, notwithstanding their country of origin, the respective type of health care system and the respondents, appear to have a certain number of similar goals mainly with regards to service quality and access. Financial goals appear to be the least important throughout. Assessing the relative success of the alliance in attaining these goals was fraught with uncertainty: even though most goals were deemed to have been reached or surpassed by the respondents, no objective data or information was available to support their opinion. This lack could be traced to insufficient provisions regarding goals, targets and monitoring in the alliance structure, governance or written agreements. Available data generated a three tier model of alliance success which bears many similarities with other alliance models insofar as alliance characteristics impact the way the alliance works which in turn predicts its success or performance. Alliances have enabled certain private sector industries and corporations to prosper, but not in all cases. In the public health sector, it seems that their first function is to help hospitals survive and maintain a sufficient level and number of services, in the face of unprecedented financial stress.

\section{REFERENCES}

[1] Sivadas, E., \& Dwyer, F. R. (2000). An Examination of Organizational Factors Influencing New Product Success in Internal and Alliance-Based Processes. Journal of Marketing, 64 (1), 31-49

[2] Faems, D., Janssens, M., Madhok, A., \& Looy, B. V. (2008). Toward an Integrative Perspective on Alliance Governance: Connecting Contract Design, Trust Dynamics, and Contract Application. The Academy of Management Journal, 51 (6), 1053-1078.

[3] Hoetker, G., \& Mellewigt, T. (2009). Choice and performance of governance mechanisms: matching alliance governance to asset type. Strategic Management Journal, 30 (10), 1025-1044.

[4] Gulati, R. (1998). Alliances and networks. Strategic Management Journal, 19, 293-317.

[5] Gulati, R., \& Singh, H. (1998). The Architecture of Cooperation: Managing Coordination Costs and Appropriation Concerns in Strategic Alliances. Administrative Science Quarterly, 43 (4), 781-814.
[6] Williamson, O. E. (1985). The Economic Institutions of Capitalism: firms, markets, relational contracting. New York: Free Press.

[7] Albers, S., Wohlgezogen, F., \& Zajac, E.J. (2013). Strategic Alliance Structures: An Organization Design. Journal of Management, May. Retrieved at http://jom.sagepub.com/con tent/early/2013/05/24/0149206313488209

[8] Emden, Z., Yaprak, A., \& Cavusgil, S. T. (2005). Learning from experience in international alliances: antecedents and firm performance implications. Journal of Business Research, 58 (7), 883-892.

[9] Draulans, J., deMan, A. P., \& Volberda, H. W. (2003). Building Alliance Capability:: Management Techniques for Superior Alliance Performance. Long Range Planning, 36 (2), 151-166.

[10] Kale, P., \& Singh, H. (2009). Managing Strategic Alliances: What Do We Know Now, and Where Do We Go From Here? The Academy of Management Perspectives, 23 (3), 45-62.

[11] Judge, W. Q., \& Dooley, R. (2006). Strategic Alliance Outcomes: a Transaction-Cost Economics Perspective. British Journal of Management, 17 (1), 23-37.

[12] Volery, T., \& Mansik, S. (1998). The role of trust in creating effective alliances: A managerial perspective. Journal of Business Ethics, 17 (9-10), 987-994.

[13] Mohr, J., \& Spekman, R. (1994). Characteristics of Partnership Success: Partnership Attributes, Communication Behavior, and Conflict Resolution Techniques. Strategic Management Journal, 15(2), 135-152.

[14] Zaman, M. \& Mavondo, F. T. (2008). Measuring alliance success: A conceptual framework. Retrieved at http://academic.research.microsoft.com/Paper/6178145.aspx

[15] Whipple, J. M., \& Frankel, R. (2000). Strategic Alliance Success Factors. Journal of Supply Chain Management, 36 (3), 21-28.

[16] Das, T. K., \& Teng, B. S. (2003). Partner analysis and alliance performance. Scandinavian Journal of Management, 19, 279-308.

[17] Bazzoli, G. J., Chan, B., Shortell, S. M., \& D'Aunno, T. (2000) The financial performance of hospitals belonging to health networks and systems. Inquiry: a journal of medical care organization, provision and financing, 37, 234-252.

[18] Nurkin, H. A. (2002). The Creation of a Multiorganizational Health Care Alliance: The Charlotte-Mecklenburg Hospital Authority. In A.D.Kaluzny, H. S. Zuckerman, \& T. C. Ricketts (Eds.) Partners: Forming Strategic Alliances in Health Care, (pp. 63-67). Washington: Beard Books.

[19] Ahgren, B. (2008). Is it better to be big? The reconfiguration of 21 st century hospitals: Responses to a hospital merger in Sweden. Health Policy, 87, 92-99.

[20] Levine, J. B. \& Byrne, J. A. (1986). Corporate odd couples. Business Week, 21, 100-106.

[21] Lunnan, R. \& Haugland, S. A. (2008). Predicting and measuring alliance performance: a multidimensional analysis. Strategic Management Journal, 29, 545-556.

[22] Stein, B. A. (2002). Strategic alliances: Some lessons from experience. In A.D.Kaluzny, H. S. Zuckerman, \& T. C. 
Ricketts (Eds.), Partners: Forming Strategic Alliances in Health Care (pp. 19-34). Washington: Beard Books.

[23] Collerette, P. \& Heberer, M. (2013). Governance of Hospital Alliances: Lessons Learnt from 6 Hospital and Non-Hospital Cases. Gesundheitswesen, 75, 1-4.

[24] Lethbridge, J. (2014). Public enterprises in the healthcare sector - a case study of Queen Elizabeth Hospital, Greenwich, England. Journal of Economic Policy Reform, 17(3), 224-235. doi: 10.1080/17487870.2014.909314

[25] Moore, D. W. (2004). Public: Healthcare Costs and Availability Are Major Concerns (pp. 339-342): Gallup Poll News Service.

[26] Powell, T. (2008). Carrots and Sticks: Keeping Healthcare Workers on the Job in a Public Health Disaster. American Journal of Bioethics, 8(8), 20-21. doi: 10.1080/15265160802 318154

[27] Chan, C.-L., Huang, H.-T., \& You, H.-J. (2012). Intelligence modeling for coping strategies to reduce emergency department overcrowding in hospitals. Journal of Intelligent Manufacturing, 23(6), 2307-2318. doi: $10.1007 / \mathrm{s} 10845-011-0574-9$

[28] Fogarty, E., Saunders, J., \& Cummins, F. (2014). The Effect of Boarders on Emergency Department Process Flow. Journal of Emergency Medicine (0736-4679), 46(5), 706-710. doi: 10.1016/j.jemermed.2013.08.111

[29] Hoyle, L. (2013). Condition Yellow: A Hospital-Wide Approach to ED Overcrowding. JEN: Journal of Emergency Nursing, 39(1), 40-45. doi: 10.1016/j.jen.2011.07.020

[30] Khanna, S., Boyle, J., Good, N., \& Lind, J. (2012). Unravelling relationships: Hospital occupancy levels, discharge timing and emergency department access block. Emergency Medicine Australasia: EMA, 24(5), 510-517. doi: 10.1111/j.1742-6723.2012.01587.x

[31] Khanna, S., Boyle, J., \& Zeitz, K. (2014). Using capacity alert calls to reduce overcrowding in a major public hospital. Australian Health Review, 38(3), 318-324. doi: 10.1071/AH13103

[32] Shah, M., Punjani, N. S., Meghani, S. R., \& Bhanji, S. M. (2014). Assessing Issues of Overcrowding in Emergency Room of a Tertiary Care Hospital. International Journal of Nursing Education, 6(2), 220-225. doi:

\section{$10.5958 / 0974-9357.2014 .00638 .2$}

[33] Hegji, C. E., \& Self, D. R. (2009). The Impact of Hospital Quality on Profits, Volume, and Length of Stay. Health Marketing Quarterly, 26(3), 209-223. doi: $10.1080 / 07359680903263615$

[34] Jha, A. K., Li, Z., Orav, E. J., \& Epstein, A. M. (2005). Care in U.S. hospitals--the Hospital Quality Alliance program. The New England Journal of Medicine, 353(3), 265-274.

[35] Curtis, R. S. (2001). Successful Collaboration Between Hospitals and Physicians: Process or Structure? Hospital Topics, 79(2), 7-13.

[36] Morrissey, J. (2014). Strategic IT Alliances. (cover story). Trustee, 67(2), 8-12.

[37] Kaushal, K. (2014). Social desirability bias in face to face interviews. Journal of Postgraduate Medicine, 60(4), 415-416. doi: $10.4103 / 0022-3859.143989$

[38] Krumpal, I. (2013). Determinants of social desirability bias in sensitive surveys: a literature review (English). Quality \& Quantity, 47(4), 2025-2047.

[39] Wildhaber, F., Collerette, P., Pelletier, D., \& Heberer, M. (2015). Benchmarking inter-hospital alliances against industry best practices, (unpublished manuscript). Basel, Switzerland: Institute of Surgical Research and Hospital Management.

[40] Corbiere, M., \& Lariviere, N. (2014). Qualitative, Quantitative and Mixed Methods for Research in Social, Human and Health Sciences [French]. Montreal: Presses de l'Université du Québec.

[41] Cullen, J. B., Johnson, J. L., \& Sakano, T. (2000). Success through commitment and trust: The soft side of strategic alliance management. Journal of World Business, 35, 223-240. http://dx.doi.org/10.1016/S1090-9516(00)00036-5

[42] Johnson, J. L., Cullen, J. B., \& Sakano, T. (1996). Opportunistic Tendencies in IJVs with the Japanese: The Effects of Culture, Shared Decision Making, and Relationship Age. International Executive, 38(1), 79-94.

[43] Heimeriks, K.H., \& Duysters, G. (2007). Alliance capability as a mediator between experience and alliance performance: An empirical investigation into the alliance capability development process. Journal of Management Studies, 44(1), $25-49$ 